\title{
EXPERIMENTAL STUDY OF TEMPERATURE RISE AND EARLY- AGE THERMAL CRACK CONTROL IN CONCRETE
}

\author{
Ruthwik Chala ${ }^{1}$, Mourougane $\mathbf{R}^{2}$ \\ ${ }^{1}$ Research Scholar, Department of Civil Engineering, M.S.Ramaiah Institute of Technology, Karnataka, India \\ ${ }^{2}$ Assistant Professor, Department of Civil Engineering, M.S.Ramaiah Institute of Technology, Karnataka, India
}

\begin{abstract}
The issues related to thermal cracking of concrete at early age are discussed in this paper. The main cause of these cracks are inhomogeneous volume changes associated with thermal and moisture gradients occurring in concrete structures which affects the durability of structure, serviceability or its appearance. The experimental study was carried out on six cast in-place reinforced concrete slabs and three reinforced thick concrete walls of different section thicknesses to determine the peak temperature rise in the structure, which was determined using temperature sensor (Thermocouple). Results obtained in the study indicated different peak rise in temperature for different section thickness, it was also studied that slabs and walls of same section thickness, produced nearly same peak temperature rise in the structure. The paper also discusses crack control measure by provision of distribution reinforcement to prevent early age thermal cracking based on the thermal data's obtained in the field. The design is carried out as per the available provisions in Indian code for the field data's, and the design results are compared with the available data's in Indian codes..
\end{abstract}

Keywords: Mass Concrete, Peak rise in temperature, Thermal gradient, Section thickness, Thermal cracks

\section{INTRODUCTION}

Thermal cracking in concrete structures mainly occurs due to excessive temperature difference in the section (i.e. Thermal gradient). This causes cooler portion to contract and warmer portion to expand, and when there is restraint from warmer portion against the contraction from cooling, thermal cracks are induced in the structure. In other words concrete expand and contract when exposed to hot and cold ambient temperature respectively, and cracking will occur when the bulk volume change resulting from temperature variation is restrained. Thermal cracking at early age is generally associated with release of heat from cement which is an exothermic reaction. Here the term early age covers only an insignificant amount of time in the total life of concrete, but during this period numerous options are performed such as mixing, transporting to job site, placements in forms, consolidation, finishing, curing and removal of formwork. These operations are affected by the characteristics of fresh concrete, like workability and setting time. Obviously, the control of both early-age operations and properties of fresh concrete is essential to ensure that the finished element is structurally adequate for the purpose for which it was designed. To avoid concrete surface cracking due to heat generated in concrete structures, a limit on maximum difference in temperature at centre of section and ambient is suggested as $20^{\circ} \mathrm{C}[1,2,3]$. There is an popular assumption that properties and consumption of mass concrete are of interest only those who are involved in design and construction of dams, but structures like concrete piers, walls, slabs and foundations which are several meters thick and are made with high strength concrete or normal strength concrete but much smaller than dams can face the problem of thermal cracking as serious as in case of dams.
As per ACI 116R, mass concrete is defined as "any volume of concrete with dimension large enough that measures to be taken to cope with generation of heat and attendant volume change in minimizing cracking"[4]. Because it is not a precise definition, some measures are proposed to estimate the early thermal cracking tendency, one of them proposed by Flaga is related to surface modulus [5].

$$
m=\frac{s}{v}
$$

Where $\mathrm{S}$ is the area of surface and $\mathrm{V}$ is volume of element. According to the above mentioned proposal, the concrete element is defined as mass or thick element that is sensitive to early age thermal effect where $m<2$. In such element expected temperature is greater than $20^{\circ} \mathrm{C}$. When $2 \leq \mathrm{m} \leq$ 15 the element is defined as medium thick and expected increase in temperature is greater than $20^{\circ} \mathrm{C}$. The factors that affects the temperature rise as well as temperature difference in concrete section mainly depends on section thickness, formwork and insulation, cement type, concrete mix proportions, placing and ambient conditions [6].

\subsection{Research Significance}

A large amount of researches have been carried out aimed at minimizing and controlling and minimizing early age thermal cracks in concrete. The heat of hydration of concrete has been one of the most important issues investigated. There are many criteria for assessment of the hydration of heat induced cracks. Some provisions adopt stress based assessment as well as temperature based assessment. Temperatures can be readily assessed by field measurements as well as analysis using finite element 
programs, and the reliability of temperature measurement is significantly higher than that of stress based measurements. Consequently, temperature based assessment has been frequently employed in practice to approximately decide the probability of occurrence of cracks based on temperature difference. The purpose of this study is to determine the differential temperature for both slabs and walls as a conditions of internal and external restraints, and to determine the crack spacing and area of steel required to prevent thermal cracking in concrete at early age using the existing cracking assessment as per the specification of Indian standard codes. Hence this study can be used to compare and validate the results of peak rise in temperature by conducting thermal analysis and modeling that can predict temperature distribution within the structure.

\section{EXPERIMENTAL PROGRAM AND SCHEME OF STUDY}

The experimental program in this study was to measure and monitor temperature rise for slabs and walls of different section thickness. Experimentation were carried out on actual slabs and walls involved in construction of Bangalore underground Metro rail project (UG-Phase II). Temperature measurements were done using thermocouple K-type, which were being embedded upto mid-depth of the concrete section. In the present study $\mathrm{M}_{35}$ grade concrete is being adopted with mix proportion of cement $=320 \mathrm{~kg} / \mathrm{m}^{3}$, water $=172 \mathrm{~kg} / \mathrm{m}^{3}$, sand $=757 \mathrm{~kg} / \mathrm{m}^{3}, 12.5 \mathrm{~mm}$ coarse aggregate $=$ $535 \mathrm{~kg} / \mathrm{m}^{3}, 20 \mathrm{~mm}$ coarse aggregate $=535 \mathrm{~kg} / \mathrm{m}^{3}$, fly ash $=$ $80 \mathrm{~kg} / \mathrm{m}^{3}$, admixture $=3.40 \mathrm{~kg} / \mathrm{m}^{3}, \mathrm{w} / \mathrm{c}$ ratio $=0.43$. Type of formwork used in construction of both slabs and walls were $18 \mathrm{~mm}$ thick laminated plywood. Before casting of concrete a small quantity of concrete is obtained from RMC transit mixer into the concrete trolley in order to determine the placing temperature of concrete (which plays a vital role of producing temperature rise within the section), which can be found out by means of inserting the thermocouple in the concrete slurry as shown in Figure-1, where placing temperature of concrete was found to be around $28.3^{\circ} \mathrm{C}$.

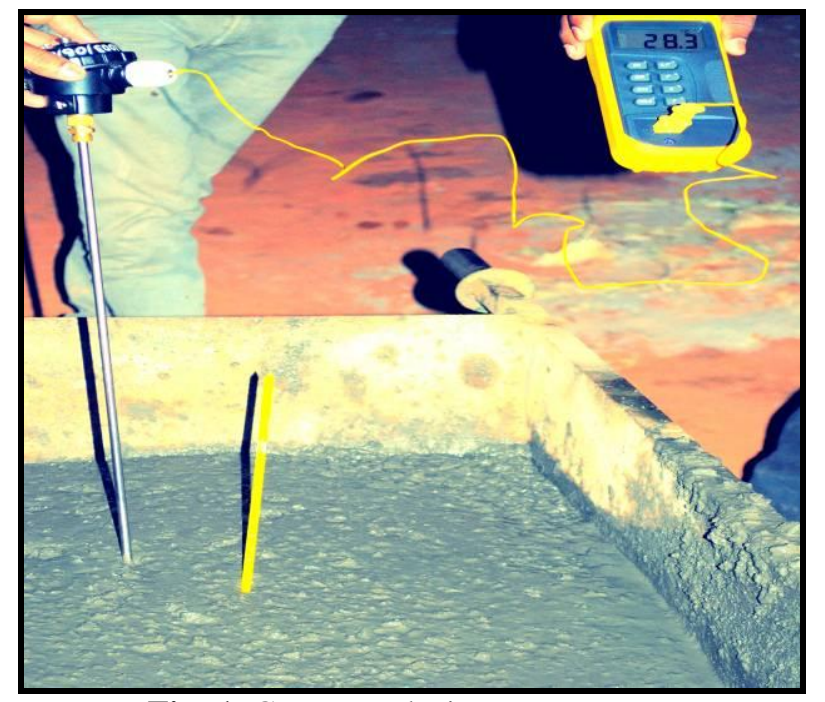

Fig -1: Concrete Placing Temperature
In this study, both slabs and walls were pre reinforced with $16 \mathrm{~mm}$ diameter bar in two layers to prevent thermal cracking. The design was carried out as per CIRIA 91, due to lack of data on peak rise in temperature of the section in Indian specifications

\subsection{Massive RCC Roof Slab}

Experimentation was carried on six slabs of different lift thickness (i.e. $400 \mathrm{~mm}, 500 \mathrm{~mm}, 600 \mathrm{~mm}, 800 \mathrm{~mm}, 1000 \mathrm{~mm}$, $1300 \mathrm{~mm}$ ). Plan area of slab was $20 \mathrm{~m}$ x $20 \mathrm{~m}$. To determine the peak rise in temperature in the structure, mild steel moulds were embedded upto mid -depth of section as shown in Figure- 2, upon which the thermocouples were mounted to sense the temperature.

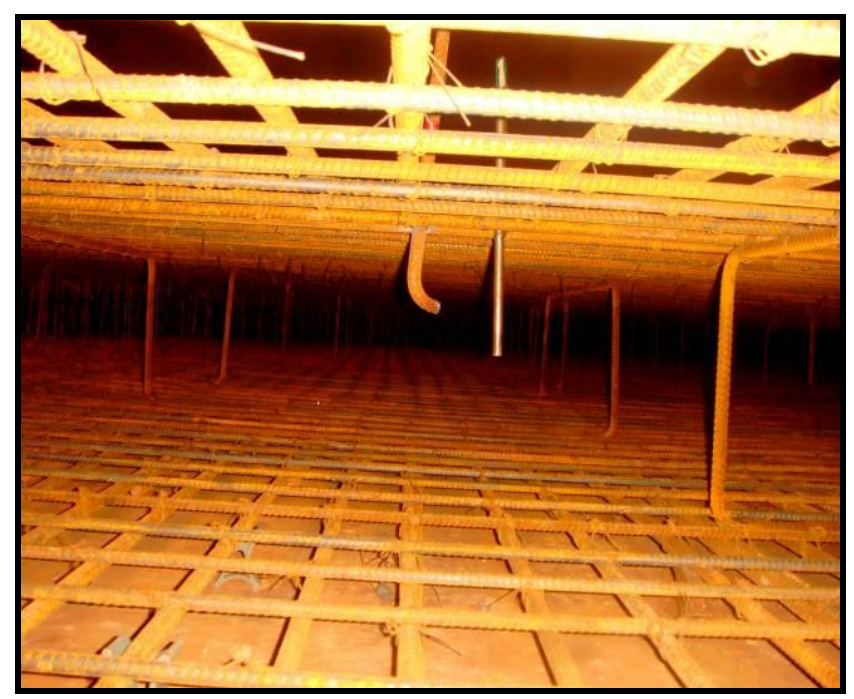

Fig -2: Moulds placed upto mid-depth of slab

The bottom opening of mould were welded with steel plate of negligible thickness, and the top opening of moulds were covered with tape, so as to prevent penetration of concrete slurry in the mould. Length of mould was equal to half of section thickness plus $100 \mathrm{~mm}$. An extra $100 \mathrm{~mm}$ projection of mould was provided so as to protect the mould against curing conditions. After casting of concrete and when concrete has set sufficiently, the covering at the upper end of mould is removed and the thermocouple are embedded inside the mould, which is in turn connected to an hand-held processed indicator and the readings are recorded. The greatest temperature was obtained in slab for $1300 \mathrm{~mm}$ section thickness which was around $63.6^{\circ} \mathrm{C}$ and it took nearly nine days for this slab to reach the ambient temperature. And minimum temperature was obtained in slab for $400 \mathrm{~mm}$ section thickness which was around $44.6^{\circ} \mathrm{C}$ and it took nearly four days to reach the ambient temperature. The results of peak rise in temperature for all sections are plotted graphically along with ambient temperature, which is as shown from Chart 1-6. It was also observed in the field conditions that surface temperature of concrete was nearly close to ambient conditions which was suggested by Barbara et al [7]. 


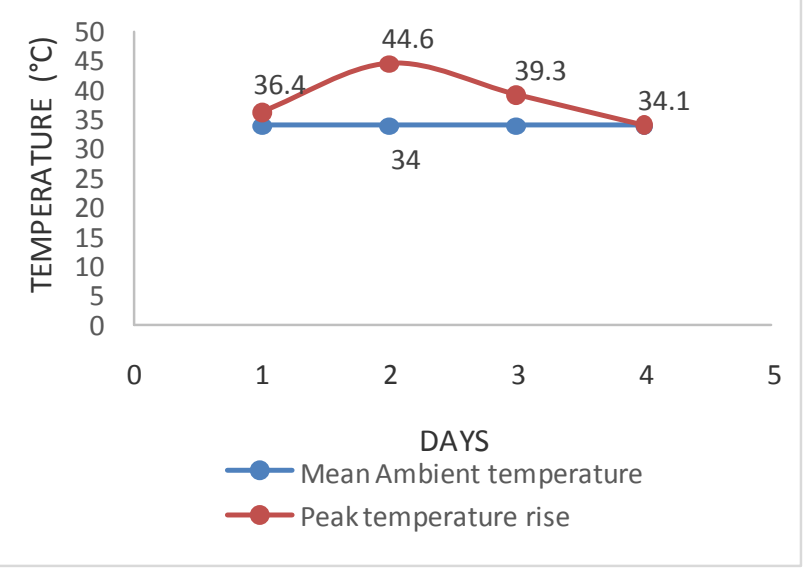

Chart -1: Temperature Variation for 400mm thick slab

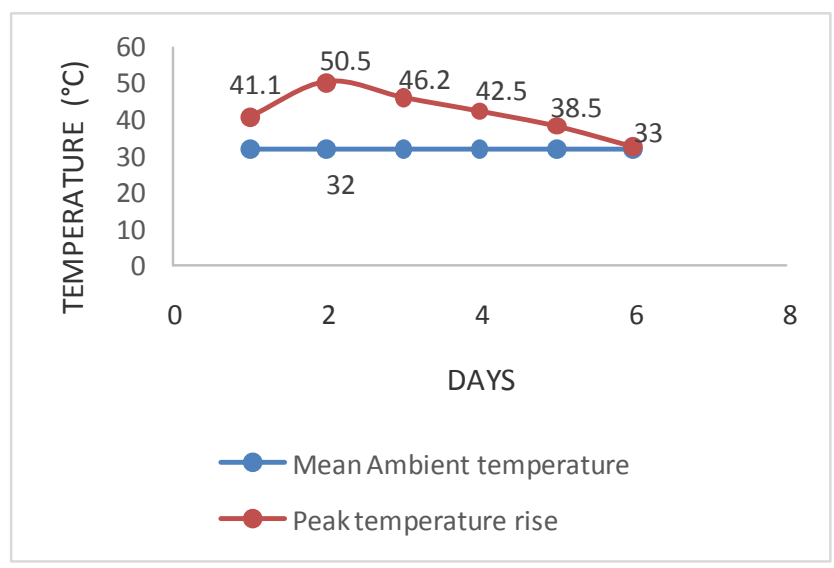

Chart -3: Temperature Variation for $600 \mathrm{~mm}$ thick slab

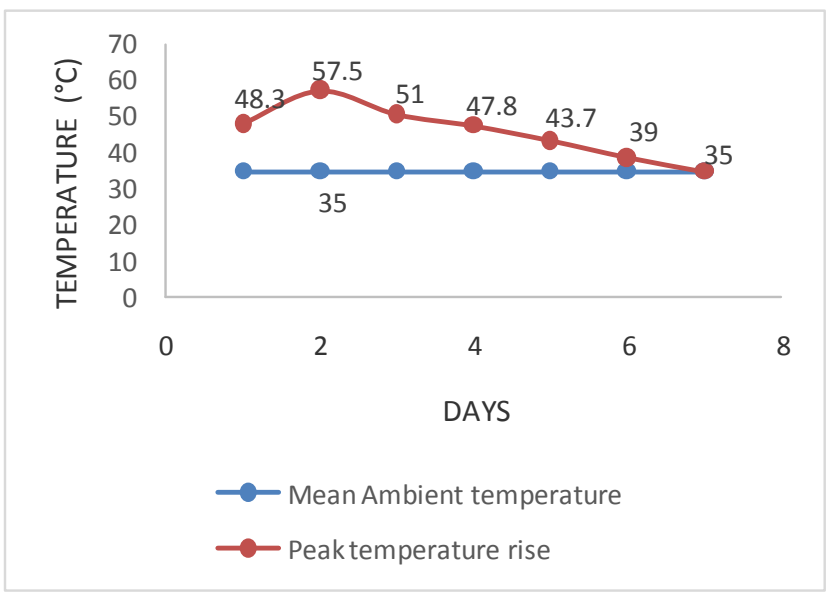

Chart -5: Temperature Variation for 1000mm thick slab

It was observed in the study that the peak rise in temperature at mid-depth of section sensed by thermocouple was obtained in slabs during the second day after casting of concrete.

\subsection{Thick RCC Wall}

Experimentation was carried out on three walls of different section thickness (i.e. $500 \mathrm{~mm}, 800 \mathrm{~mm}, 1200 \mathrm{~mm}$ ), the length

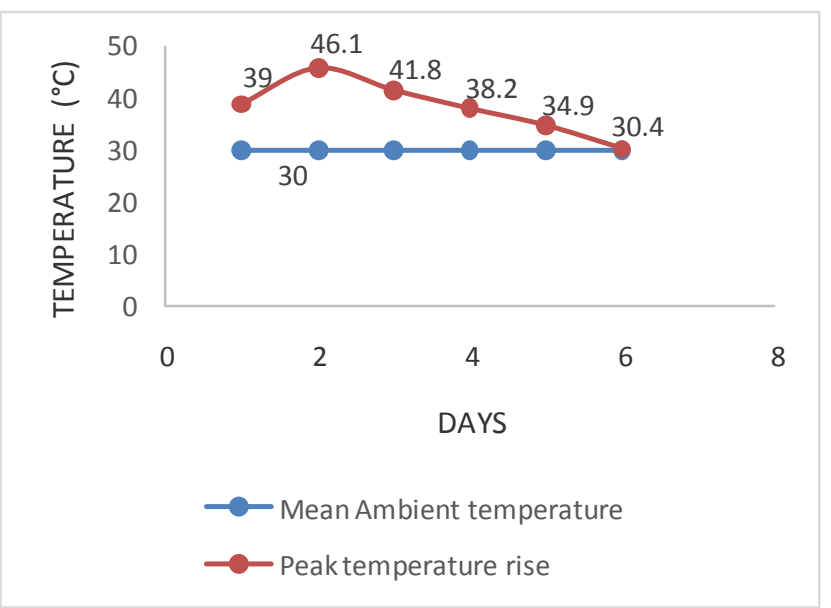

Chart -2: Temperature Variation for 500mm thick slab

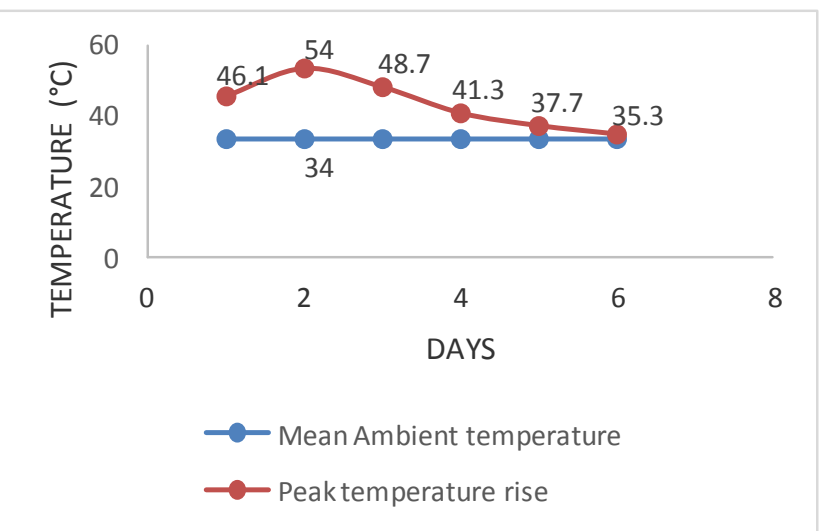

Chart -4: Temperature Variation for $800 \mathrm{~mm}$ thick slab

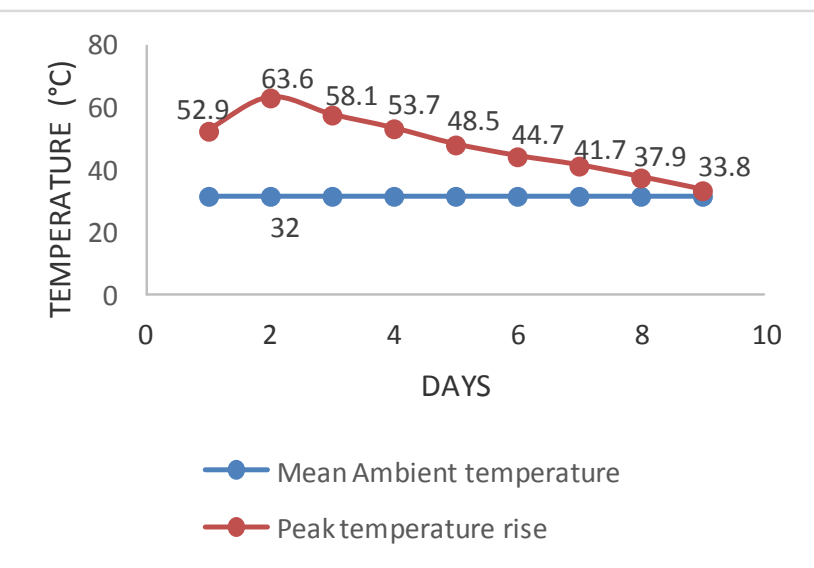

Chart -6: Temperature Variation for $1300 \mathrm{~mm}$ thick slab

of wall was $20 \mathrm{~m}$, and height being $5 \mathrm{~m}$. Similar Mix of $\mathrm{M}_{35}$ grade used for slabs was adopted for walls also. And moulds were also placed in walls upto mid-depth of section thickness which is as shown in Figure-3. The greatest temperature was obtained in wall of $1200 \mathrm{~mm}$ section thickness which was around $61.5^{\circ} \mathrm{C}$, and it took nearly nine 
days for this wall for reach ambient temperature. The results of peak rise in temperature for all sections are plotted graphically along with ambient temperature, which is as shown from Chart 7-9.

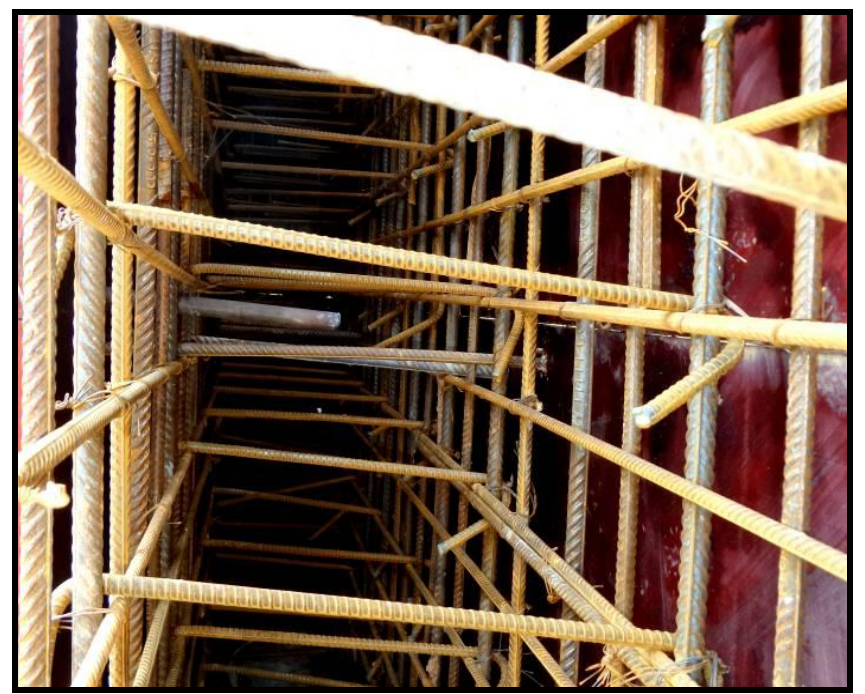

Fig -2: Moulds placed upto mid-depth of wall

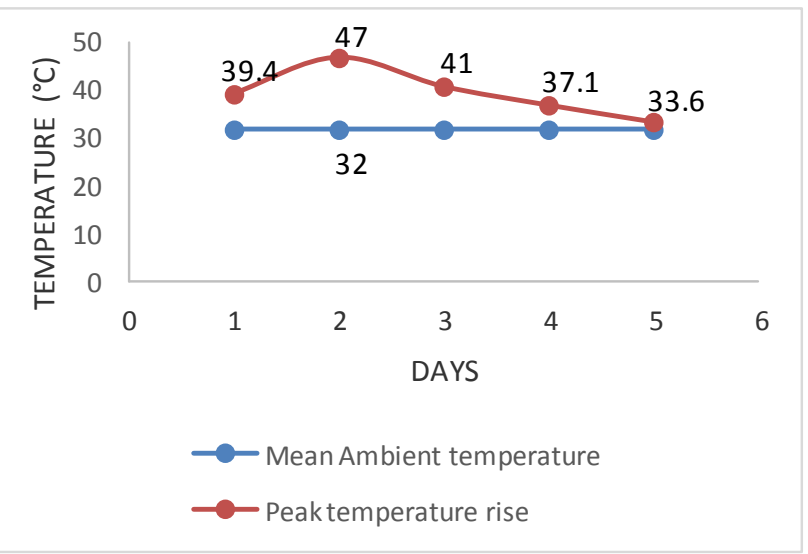

Chart -7: Temperature Variation for 500mm thick wall

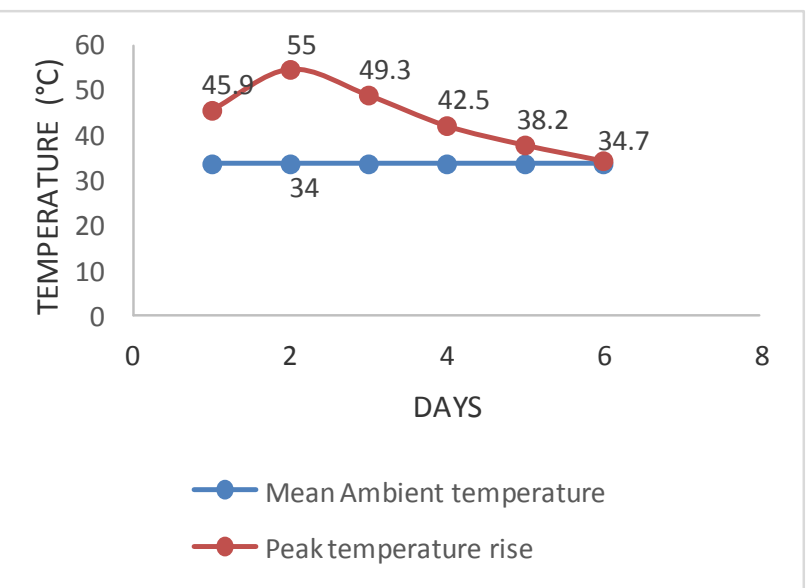

Chart -8: Temperature Variation for $800 \mathrm{~mm}$ thick wall

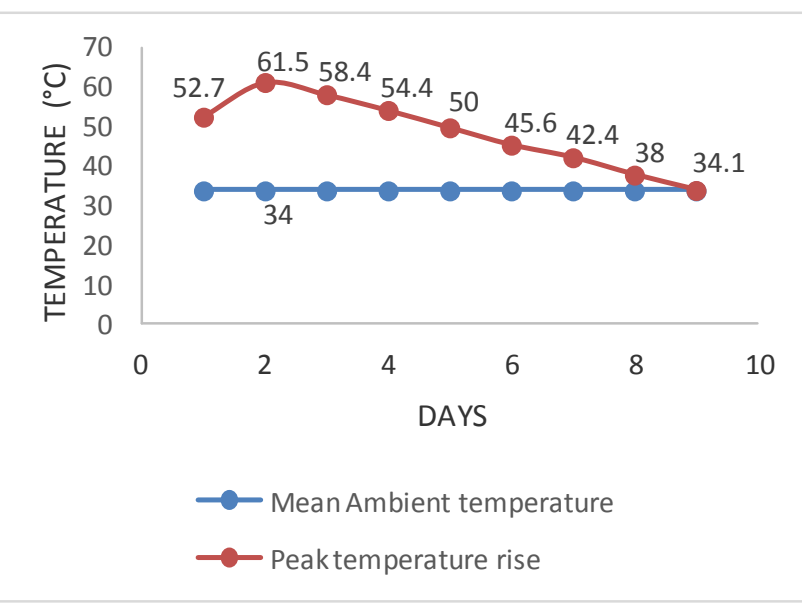

Chart -9: Temperature Variation for $1200 \mathrm{~mm}$ thick wall

\section{CONTROL OF THERMAL CRACKING}

Cracking arising from temperature and moisture changes in concrete structure can be controlled [8] by following methods [8]:

a) Provision of distribution reinforcement.

b) Using aggregates with low coefficient of thermal expansion

c) Using minimum cement content, by means of using pozzolonic materials in the mix .

d) Using cement with low rates of heat evolution

e) Using crushed ice in mix to reduce placing temperature

f) Insulation of concrete surface

But in most cases the use of distribution reinforcement parallel to each face of member is the most convenient and economical method for crack control. The distribution reinforcement should be placed as close to the surface as in consistent with the cover requirements, with full required anchorage length and distributed evenly across the perimeter of the section. In this paper the design is carried out as per the provisions of Indian code [9], for the temperature gradient values obtained in the field and the results are compared with the available data in the codal provisions. In the present study concreting was done during summer months of the season (i.e. February to May), at Bangalore location where the ambient temperature varied from $30^{\circ} \mathrm{C}$ to $35^{\circ} \mathrm{C}$. Hence a mean ambient temperature of $33^{\circ} \mathrm{C}$ was adopted to determine the temperature gradient in the section. Since the peak rise in temperature for section thickness of $500 \mathrm{~mm}$ and $800 \mathrm{~mm}$ for both type of structural member was nearly same, hence the maximum value obtained is used for design of reinforcement to prevent thermal cracks in concrete at early age. The thermal gradient values obtained for all the section thickness considered are presented in Table-1, and the crack spacing and area of steel obtained as per design results are presented in Table- 2 . 
Table -1: Thermal gradient values obtained as per field observations

\begin{tabular}{|c|c|c|c|}
\hline $\begin{array}{c}\text { Section } \\
\text { thickness }\end{array}$ & $\begin{array}{c}\text { Peak } \\
\text { temperature } \\
\text { rise }\end{array}$ & $\begin{array}{c}\text { Mean } \\
\text { ambient } \\
\text { temperature }\end{array}$ & $\begin{array}{c}\text { Thermal } \\
\text { gradient }\end{array}$ \\
\hline $400 \mathrm{~mm}$ & $44.6^{\circ} \mathrm{C}$ & $33^{\circ} \mathrm{C}$ & $11.6^{\circ} \mathrm{C}$ \\
\hline $500 \mathrm{~mm}$ & $47.0^{\circ} \mathrm{C}$ & $33^{\circ} \mathrm{C}$ & $14.0^{\circ} \mathrm{C}$ \\
\hline $600 \mathrm{~mm}$ & $50.5^{\circ} \mathrm{C}$ & $33^{\circ} \mathrm{C}$ & $17.5^{\circ} \mathrm{C}$ \\
\hline $800 \mathrm{~mm}$ & $55.0^{\circ} \mathrm{C}$ & $33^{\circ} \mathrm{C}$ & $22.0^{\circ} \mathrm{C}$ \\
\hline $1000 \mathrm{~mm}$ & $57.5^{\circ} \mathrm{C}$ & $33^{\circ} \mathrm{C}$ & $24.5^{\circ} \mathrm{C}$ \\
\hline $1200 \mathrm{~mm}$ & $61.5^{\circ} \mathrm{C}$ & $33^{\circ} \mathrm{C}$ & $28.5^{\circ} \mathrm{C}$ \\
\hline $1300 \mathrm{~mm}$ & $63.6^{\circ} \mathrm{C}$ & $33^{\circ} \mathrm{C}$ & $30.6^{\circ} \mathrm{C}$ \\
\hline
\end{tabular}

The three main steps involved in design is to determine the cracking spacing for estimated maximum crack width, and based on crack spacing, number of bars per meter width are determined and finally the area of steel is provided based on the number of bars obtained. Here the crack spacing can be obtained using the expression:

$$
\text { Wmax }=\operatorname{Smax} x \frac{\propto}{2} x\left(T_{1}+T_{2}\right)-
$$

Where,

Wmax $=$ estimated maximum crack width

Smax $=$ Crack spacing

$\alpha=$ coefficient of thermal expansion of concrete

$T_{1}=$ Fall in temperature between hydration peak and ambient (i.e. thermal gradient)

$T_{2}=$ Fall in temperature due to seasonal variation

And based on the crack spacing value, the number of bars can be determined, based on which area of steel can also be obtained:

$$
n_{b .} \Phi \geq \frac{\mathrm{fct}}{\mathrm{fb}} \times \frac{2 \mathrm{bD}}{\Pi \operatorname{Smax}}
$$

Where,

$n_{b}=$ number of bars.

$\Phi=$ diameter of bar.

$\frac{\mathrm{fct}}{\mathrm{fb}}=$ ratio of tensile strength of concrete to average bond

strength between concrete and steel, taken as unity for plain round bars, 2/3 for deformed bars.

$b=$ width of section.

$D=$ surface zone thickness.

Smax $=$ obtained from $\mathrm{W} \max$.

In equation (2), the estimated maximum crack width (i.e. Wmax) is taken as $0.2 \mathrm{~mm}$ as per the guidelines given in IS 3370 (Part-2):2009, and the value of coefficient of thermal expansion of concrete (i.e. $\alpha$ ) is taken as $8.25 \times 10^{-6} /{ }^{\circ} \mathrm{C}$ which is the average value taken as per the provisions mentioned in IS 456-2000 [10]. The value of $\mathrm{T}_{1}$ are substituted in equations as 2 as per the obtained observation results in the field, and the value of T2 (i.e. fall in temperature due to seasonal variation) can be obtained from the metrological department of the region. In this study the location was Bangalore region, hence the seasonal variation according to this region is considered, which is as shown in Figure-3.

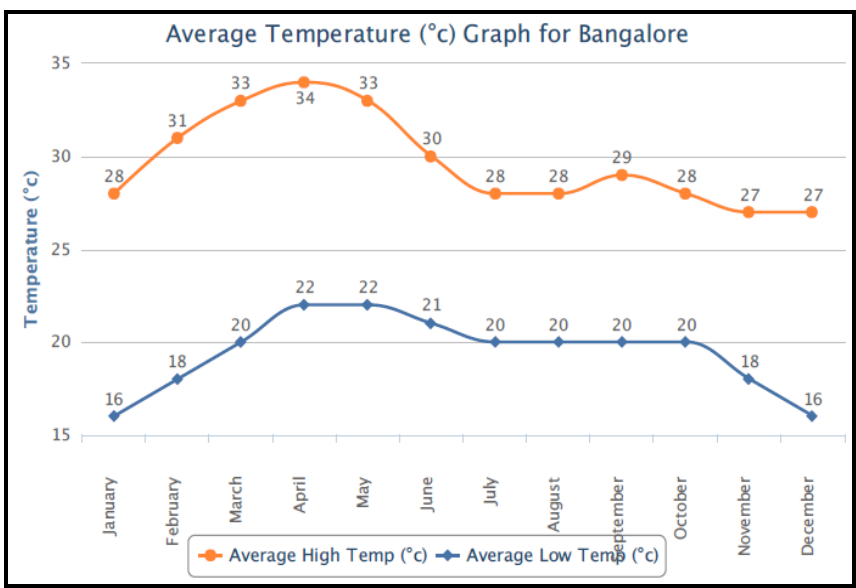

Fig -3: Seasonal variation of temperature

Since the concreting in the study was carried out during summer months of the season (i.e. February to May), the seasonal variation are also considered for this months, which is around $13^{\circ} \mathrm{C}$.

In equation 3, the surface zone thickness (i.e. D) as per IS 3370 (Part-2):2009 is taken as follows:

a) For D $<500 \mathrm{~mm}$, assume each reinforcement face controls D/2 depth of concrete

b) For D > 500mm assume each reinforcement face controls $250 \mathrm{~mm}$ depth of concrete, ignoring any central core beyond this surface depth.

\section{RESULTS}

Table -2: Design results

\begin{tabular}{|c|c|c|c|}
\hline $\begin{array}{c}\text { Section } \\
\text { thickness }\end{array}$ & $\begin{array}{c}\text { Thermal } \\
\text { gradient } \\
\left(\mathbf{T}_{\mathbf{1}}\right)\end{array}$ & $\begin{array}{c}\text { Crack } \\
\text { spacing } \\
\text { (Smax) }\end{array}$ & $\begin{array}{c}\text { Area of steel } \\
\text { (Ast) using } \\
\mathbf{1 6 m m ~} \mathbf{\Phi}\end{array}$ \\
\hline $400 \mathrm{~mm}$ & 11.6 & $1970.9 \mathrm{~mm}$ & $541.30 \mathrm{~mm}^{2}$ \\
\hline $500 \mathrm{~mm}$ & 14.0 & $1795.7 \mathrm{~mm}$ & $742.60 \mathrm{~mm}^{2}$ \\
\hline $600 \mathrm{~mm}$ & 17.5 & $1589.7 \mathrm{~mm}$ & $838.91 \mathrm{~mm}^{2}$ \\
\hline $800 \mathrm{~mm}$ & 22.0 & $1385.3 \mathrm{~mm}$ & $962.78 \mathrm{~mm}^{2}$ \\
\hline $1000 \mathrm{~mm}$ & 24.5 & $1292.9 \mathrm{~mm}$ & $1031.40 \mathrm{~mm}^{2}$ \\
\hline $1200 \mathrm{~mm}$ & 28.5 & $1168.3 \mathrm{~mm}$ & $1141.50 \mathrm{~mm}^{2}$ \\
\hline $1300 \mathrm{~mm}$ & 30.6 & $1112.0 \mathrm{~mm}$ & $1199.20 \mathrm{~mm}^{2}$ \\
\hline
\end{tabular}

The area of steel values obtained are compared with the minimum area of steel required as per the provisions mentioned in IS 3370 (Part-2):2009, which is given as $0.29 \% \mathrm{bD}$ for $\mathrm{M}_{35}$ grade of concrete, and based on this expression we get $\mathrm{Ast}_{\min }$ for section thickness less than $500 \mathrm{~mm}=580 \mathrm{~mm}^{2}$, and for section thickness greater than $500 \mathrm{~mm}=725 \mathrm{~mm}^{2}$. Also the area of steel values obtained for the section thickness considered in this study can be compared with the data's available in IS 3370 (Part-2):2009, where the codal provision consider the value of fall in temperature between hydration peak and ambient as $30^{\circ} \mathrm{C}$. And based on this thermal gradient value we obtain the value of crack spacing $=1127.56 \mathrm{~mm}$, with area of steel $=$ $1182.7 \mathrm{~mm}^{2}$. 


\section{CONCLUSION}

Control of thermal cracking in concrete at early age is of great importance to ensure the desired life of the structure. In this paper it was demonstrated that as the section thickness increased, peak rise in temperature also increased. It was also observed that slabs and walls of same thickness (i.e. $500 \mathrm{~mm}$ and $800 \mathrm{~mm}$ ) whether internal or external restraint, produced nearly same peak rise in temperature, which was around $47^{\circ} \mathrm{C}$ for $500 \mathrm{~mm}$ thick section and around $55^{\circ} \mathrm{C}$ for $800 \mathrm{~mm}$ thick section. The study also demonstrated the crack control measure, by means of provision of distribution reinforcement which is the most economical method to prevent thermal cracks in concrete structure. It was also observed that for section thickness less than $500 \mathrm{~mm}$, minimum area of steel of $0.29 \% \mathrm{bD}$ (for $\mathrm{M}_{35}$ concrete grade) satisfies the requirement to prevent thermal cracks in structure at early age, but however the area of steel obtained for section thickness greater than $500 \mathrm{~mm}$, was significantly lesser compared to codal provisions, which is sufficient to prevent thermal cracks in structure at early age. It is also recommended for design engineers, involved in mass concrete construction to use the values of peak rise in temperature obtained from the present study for $\mathrm{M}_{35}$ grade of concrete, and where ambient temperature are in the range of $30^{\circ} \mathrm{C}-35^{\circ} \mathrm{C}$, and where plywood forms are used for construction.

\section{ACKNOWLEDGEMENTS}

The study was made possible by the support of Bangalore metro rail corporation limited (BMRCL). The authors grateful to CEC-SOMA-CICI JV and Costal consultants for their assistance. We also thank Mr. Yongendra (Project manager) and Mr. Harsha.G.M (Design and project consultant) for their assistance and use of BMRCL facilities.

\section{REFERENCES}

[1]. European Standard ENV 206(1992), Concrete: Performance, Production, Placing and compliance criteria, BSI Standards.

[2]. Florida Dept of Transportation (FDOT).(2007)."Standard specifications for road and bridge construction." Tallahassee, FL.

[3]. Neville,A.M (1998). Properties of concrete, John Wiley and sons, Inc.

[4]. ACI 116R-8 (1985), 'Cement and ConcreteTerminology' American Concrete Institute, Michigan.

[5]. Flaga.K, "Macro self-induced thermal stresses in concrete element structures", Monography 106 of Cracow technical university, 1990.

[6]. T.A.Harrison,"Early-age thermal crack control in concrete, CIRIA Report 91, 1992.

[7]. Barbara, Agnieszka, "Early age thermal and shrinkage cracks in concrete structure - Influence of geometry and dimension of structure", Architecture Civil Engineering Environment, No 3, 2011, pp 55-70.

[8]. British Standards Institution, "Design of concrete structures for retaining aqueous liquids" BS 8007: 1987.
[9]. Bureau of Indian Standards, "Concrete structure for storage of liquid-Code of practice", IS 3370 (Part2):2009.

[10]. Bureau of Indian Standards, "Plain and Reinforced Concrete-Code of practice", IS 456:2000.

\section{BIOGRAPHIES}

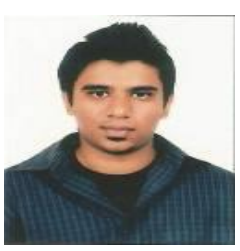

Ruthwik Chala, is a Post graduation student, who is pursuing his M-tech in the field of Structural engineering, at M.S. Ramaiah Institute of Technology, Bangalore.

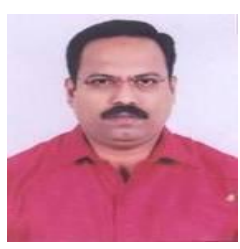

Mourougane $\mathbf{R}$ is working as Assistant Professor in Civil Engineering Department at M.S. Ramaiah Institute of Technology, Bangalore. My area of interest in Research is Structural Materials like Geopolymer and SCC. 